\title{
eClinics Integration Techniques for Clinical Information Systems Moving into a National Network
}

\author{
Dr. V. Dinusha BSc(ICT) \\ Temporary Academic Staff, University of Colombo School of Computing \\ 35, Reid Avenue, Colombo 7, Sri Lanka. \\ E-Mail address: din@ucsc.cmb.ac.lk
}

Dr. S. M. K. D. Arunatileka BSc, MBA, PhD

Senior Lecturer, University of Colombo School of Computing, 35, Reid Avenue, Colombo 7, Sri Lanka.

E-Mail address: sda@ucsc.cmb.ac.lk

\section{Dr. K. R. P. Chapman MD, MS, FRCSE}

Consultant Surgeon, Base Hospital Chilaw, Sri Lanka

E-Mail address: keith_rpc@hotmail.com

\section{Dr. S. Saatviga BSc(ICT)}

Temporary Academic Staff, University of Colombo School of Computing, 35, Reid Avenue, Colombo 7, Sri Lanka.

E-Mail address: sat@ucsc.cmb.ac.lk

\section{Dr. C. S. Abeywardhana BCS}

Temporary Research Assistant, University of Colombo School of Computing, 35, Reid Avenue, Colombo 7, Sri Lanka.

E-Mail address: csa@ucsc.cmb.ac.lk

Sri Lanka Journal of Bio-Medical informatics 2011:2(4):130-143

DOI: http://dx.doi.org/10.4038/sljbmi.v2i4.2257

\begin{abstract}
Patients in rural areas in developing countries have less access to specialised consultations within their hometown. They are required to incur a great cost, time and effort to reach a health institute that provides specialized health care. Yet, it is discovered that through the utilisation of comparatively cheaper Information and Communication Technology advances, it is possible to provide better health services for developing regions. Compared to other developing nations, Sri Lanka has a good healthcare service and a relatively well developed telecom and mobile infrastructure. However, due to inequality of resource distributions, specialised care is restricted to urban areas. Hence 'ViduSuwa', an internationally recognized award winning tele-medicine solution was introduced to provide specialized healthcare facilities to the remote areas of Sri Lanka. In compliance with the health policy of Sri Lanka, the main emphasis of Vidusuwa is on setting up of eConsultation centers and eClinics to link the specialist in a general hospital in a city with a patient in a peripheral setting. This paper discusses the integration techniques for clinical information systems moving in to a wider
\end{abstract}


network using the well tested concept 'ViduSuwa'. The proof of this concept was implemented with one-to-one integration in the first stage connecting two hospitals. However when replicating the solution to other hospitals and moving in to a national network, other integration techniques must also be considered. The paper presents the methodology, architecture, features and security enforcements incorporated into the Electronic Medical Record (EMR) system which is a main component of the 'ViduSuwa' telemedicine solution, in order to ensure the sustainability and replication of the concept.

Keywords - eCliniics; eConsultations; ViduSuwa EMR; Integration; patient-to-consultant; hospital-to-eClinics; patient-to-eClinics

\section{Introduction}

The healthcare delivery setting in rural parts of Sri Lanka today exposes limited access to highly specialised consultancies. It is stated that $35 \%$ of the medical specialists in the curative sector are concentrated in the administrative district of Colombo district ${ }^{(1)}$. To overcome this problem of accessibility to specialized healthcare, ViduSuwa - a patient centric eHealth initiative was carried out by conducting eConsultations and eClinics to help the patients in remote locations to meet consultants based in cities making available specialized healthcare to many ${ }^{(2)}$. This will consist of a peripheral eClinic, a web-based EMR ${ }^{(3)}, \mathrm{m}$-Communication system $^{(4)}$ and an e-Consultation centre with a medical specialist. As the Proof of Concept, a pilot project funded by the Information and Communication Technology Agency of Sri Lanka (ICTA) was initiated connecting the Marawila Base Hospital and Dankotuwa Peripheral hospital which is situated around 33 miles away from Colombo in the Northwestern province of Sri Lanka. The hospitals are connected through a web-based EMR system along with a video-conferencing component through which a patient from his/her village peripheral hospital can consult a Specialist in the city/urban area to receive treatment with the assistance of a doctor in an eClinic. In order to replicate the solution across the country, several architectural changes need to be adapted to the web based EMR system.

After the successful implementation of the proof of this concept, a research is being carried out by the authors focusing on eClinics Integration and role based access level security implementation to the Clinical Information Systems. The pilot project involved one-to-one connection. However. when moving in to a wider network in order to replicate the solution throughout the island; several integration techniques must be considered. This includes patient-to-eClinic, patient-to-consultant and hospital-to-eClinic connections. Also in the wider network with many eClinics integrated, access rights must be enforced to users using role based access level security model.

\section{Significance of the ViduSuwa EMR System}

The web based EMR system is one of the main component of the ViduSuwa concept, as the doctors at the eClinics and the consultants/specialists at the eConsultation centers rely on the real time clinical information through the centralized web based EMR system. When technology is considered, choosing 'Open Source' was the best solution because costeffectiveness has to be looked upon in the context of a developing country. There are several EMR products available in the market, but a system that is simple to use, effective and appropriate in the context of a developing country is significant to address the above mentioned research problem. The following table (table 1) shows an evaluation of some of the Open Source EMR products available today. The limitations and issues in every system 
that made ViduSuwa EMR significant in addressing the problem are highlighted. And hence ViduSuwa EMR system was built with the appropriate features for the patient-centric telemedicine solution.

Table 1: EMR Products Evaluation

\begin{tabular}{|c|c|c|c|c|}
\hline Application & Features & License & Technology & Comments \\
\hline $\begin{array}{l}\text { FileMed } \\
\text { EMR }^{(5)}\end{array}$ & $\begin{array}{ll}\text { - } & \text { Patient Mgmt } \\
\text { - } & \text { Scheduling } \\
\text { - } & \text { User Mgmt }\end{array}$ & Proprietary & Java & $\begin{array}{l}\text { Standalone system, } \\
\text { Simple \& easy to } \\
\text { use, Strong security }\end{array}$ \\
\hline 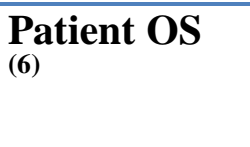 & $\begin{array}{ll}\text { - } & \text { Registration } \\
\text { - } & \text { Scheduling } \\
\text { - } & \text { Reports etc }\end{array}$ & GNU (GPL) & Java & $\begin{array}{l}\text { Standalone system, } \\
\text { customization is } \\
\text { complicated }\end{array}$ \\
\hline$\underset{(7)}{\text { Hospital OS }}$ & $\begin{array}{ll}\text { - } & \text { Registration } \\
\text { - } & \text { Work Flow Mgmt } \\
\text { - } & \text { Screening etc }\end{array}$ & GNU (GPL) & Java & $\begin{array}{l}\text { Focuses on hospital } \\
\text { information, } \\
\text { Suitable for small- } \\
\text { sized hospitals, web } \\
\text { based, Linux }\end{array}$ \\
\hline OpenEMR $^{(8)}$ & $\begin{array}{ll}\text { - } & \text { Create Patient } \\
\text { - } & \text { Patient History } \\
\text { - } & \text { Administration } \\
\end{array}$ & GNU (GPL) & php & $\begin{array}{l}\text { Standalone system, } \\
\text { Limited Features }\end{array}$ \\
\hline$\underset{(9)}{\text { OpenMRS }}$ & $\begin{array}{l}\text { - Find/ create } \\
\text { patient } \\
\text { - Administration }\end{array}$ & $\begin{array}{l}\text { OpenMRS } \\
\text { Public } \\
\text { Licence }\end{array}$ & php & $\begin{array}{l}\text { Web-based, } \\
\text { Limited Features }\end{array}$ \\
\hline Medical $^{(10)}$ & $\begin{array}{l}\text { Features beyond } \\
\text { scope }\end{array}$ & GNU (GPL) & Python & $\begin{array}{l}\text { Web-based, Linux } \\
\text {,Too slow }\end{array}$ \\
\hline GNUMed $^{(11)}$ & $\begin{array}{l}\text { - } \text { Patient Handling } \\
\text { - } \text { Medical Records } \\
\text { - } \text { Administration } \\
\text { - } \quad \text { Statistical Reports }\end{array}$ & $\begin{array}{l}\text { Free in a } \\
\text { special way, } \\
\text { modified code } \\
\text { should be } \\
\text { patented }\end{array}$ & WxPython & $\begin{array}{l}\text { Complicated, } \\
\text { Limited Features, } \\
\text { Too slow }\end{array}$ \\
\hline$\underset{(12)}{\text { Oscar EMR }}$ & $\begin{array}{ll}\text { - } & \text { Patient } \\
& \text { Registration } \\
\text { - } & \text { Scheduling } \\
\text { - } & \text { Billing } \\
\text { - } & \text { Disease Registry } \\
\text { - } & \text { Chronic disease } \\
\text { management } \\
\text { - } \text { Messaging system } \\
\text { etc. }\end{array}$ & GNU (GPL) & Java & $\begin{array}{l}\text { Hardware costs, } \\
\text { network support } \\
\text { costs high, Web- } \\
\text { based }\end{array}$ \\
\hline $\begin{array}{l}\text { ViduSuwa } \\
\text { EMR }\end{array}$ & $\begin{array}{ll}\text { - } & \text { Patient Mgmt } \\
\text { - } & \text { Scheduling } \\
\text { - } & \text { User Mgmt } \\
\text { - } & \text { Reports } \\
\text { - } & \text { SMS reminding } \\
& \text { etc }\end{array}$ & GNU (GPL) & Java & $\begin{array}{l}\text { Web-based, } \\
\text { platform } \\
\text { independent, } \\
\text { simplicity, } \\
\text { Sustainability, } \\
\text { Access Levels }\end{array}$ \\
\hline
\end{tabular}


As a result of the analysis of the EMR products that exist in the market today, it was concluded that they are not appropriate to be used in our concept context, because most of them were stand-alone systems. Some involved huge complexity overhead in customising and had features beyond our scope while some others had limited features making them inappropriate for use. Finally a decision was made to build a system that would appropriate for this simple concept and would cater to a developing country perspective with reasonable cost at a justifiable budget considering the maximum utilisation of existing technology and building upon that. The technologies used for the development of the ViduSuwa EMR system are shown in the table (table 2) next.

Table 2: Technologies Used

\begin{tabular}{ll} 
Backend \& Persistence & EJB 3.0 \& Hibernate \\
\hline Front end & Struts Framework, JQuery Framework, CSS \\
\hline Application Server & Jboss 4.2.3 \\
Build Tool & Maven \\
Testing Tool & JUnit \\
Database & MySQL Community Edition \\
\hline
\end{tabular}

EJB provides business level services, includes transaction handling, security, and Remote Method Invocation (RMI) services for the enterprise applications. Struts framework provides other frameworks like Tile and Validation frameworks and uses MVC (Model-ViewController) design pattern which provides reusability and maintainability of the code.

The EMR system is based on Multi-Tier Architecture which involves the introduction of three software layers: The Workstation, Application Server and the Database Server. The architecture is illustrated in the figure (figure 1) below.

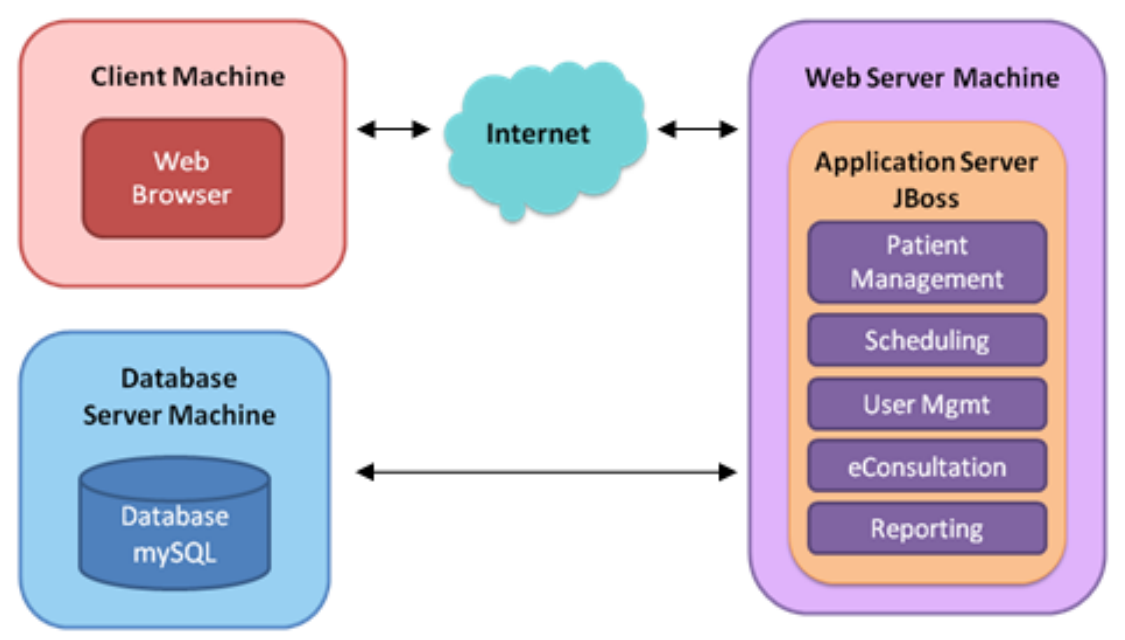

Figure 1: System Architecture of the Web-based EMR System

\section{The features and the procedure}

The Pilot project was started in June 2009 between two hospitals and the eConsultations are being carried out in the Base Hospital Marawila where the eConsultation Centre is located and at the District Hospital Dankotuwa where the eClinic is located. eClinics in the Surgical 
clinics are conducted every week with the surgical consultant from Marawila Hospital seeing patients coming to the Dankotuwa Hospital.

When the patient arrives at the peripheral eClinic he is registered in the system and a unique automatically generated eClinic ID is issued to the patient, which can be used by the system to track all patient records. A written consent is obtained from the patient for transfer of electronic medical records over the internet.

The system consists of five main modules which are Patient Management, Scheduling, User Management, My Profile and Reporting. Patient Management is the main module used for maintaining patients' medical records and the medical records are divided in to six main categories of information such as Demographic details, Clinical Notes, Investigation Reports, Medical Images, eConsultation Audio/Videos and Sketches.

The medical history of the patient is noted, a physical examination is carried out and basic symptoms and complaints are entered in to the Clinical Notes. New investigations such as lab tests, ECG, X-Rays and Scan reports are also uploaded to the system in the Investigation Reports category. Digital images of body lesions are uploaded to the system with zoom in/out features so as to help the consultant at the other end in his/her diagnosis and treatment. The system also supports uploading audio/video recordings of the conversations between the doctor, consultant and the patient. The Sketches category allows doctors to download sketch templates from the system and then scratch on them to upload the sketches to the patients' profiles. The patient and the consultant are linked via a conference tool such as Skype, Ekiga or VLC Player through internet connectivity.

The consultant is able to clearly view the investigations and images uploaded to the system by the peripheral doctor and peruse the medical records of the patient. A dialog is established between patient and the consultant through the conference tool. The consultant is able to discuss the management of the patient with the doctor in the peripheral hospital. A treatment plan is formulated and the patient advised accordingly. A follow up appointment is arranged and a printout of the clinical session is attached to the patient's clinic book. This will end the virtual eClinic Consultancy.

Scheduling module deals with scheduling, rescheduling and cancellations of eClinic appointments and theatre schedules through the system. When a consultant logs in to the system he/she will be provided with a list of patients for the eConsultation for the day with the patient count. The M-Communication system which is another component of the 'ViduSuwa' concept works with this module and sends scheduled SMS text messages on appointment dates, operation dates, cancellation and rescheduling of appointments.

Reporting was implemented for administrative purposes where reports on eClinic appointments and patient management are generated dynamically at real time. Personalization of user profiles is provided through 'My Profile' module. And the 'User Management' module deals with the users of the system and their access privileges.

\section{The TeleConsultation Roadmap}

After the successful implementation of the proof of the concept it is determined that the deployment of this telemedicine solution is important as it brings many benefits to the rural healthcare sector of Sri Lanka. Hence, an eTransformation model is developed ${ }^{(13)}$ which used 
the 7E's in eTransformation in the health sector. The fourth stage in the model is about the teleconsultation roadmap where the current position according to the eReadiness stage is mapped in the roadmap to develop a specific step-by-step path to proceed with the transformation process. The proposed teleconsultation roadmap which is adapted from the eBusiness roadmap is illustrated in the figure 2. There is an internal process as well as an external process of transformation to achieve the ideal state of convergence. This paper addresses how the external process of the eTransformation is done in the aspects of the technical solution. Several integration techniques are used for the eTransformation of external process. Since the ViduSuwa solution is proposed to be deployed in to a national network using the step-by-step approach, the necessary technical changes and security issues must be considered as it is supposed to be open to several parties in the wider network.

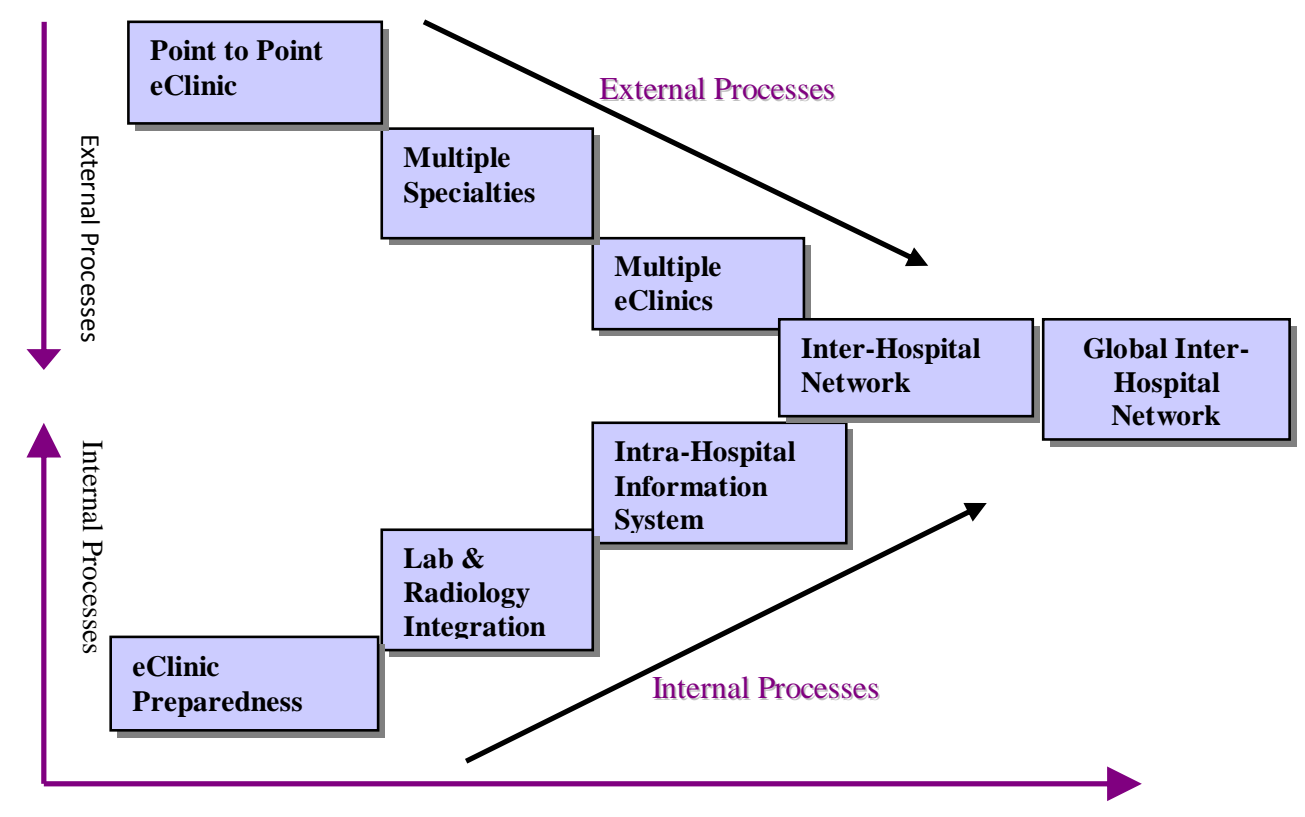

\section{Figure 2: eTeleConsultation Roadmap - Adapted from eBusiness $\operatorname{Roadmap}^{(13)}$}

\section{Integration Techniques}

The pilot project involved one-to-one integration technique, as point-to-point eClinics are easier to establish as a starting point to sense the local IT environment and introduce users to the eClinic system. The second stage would be multiple specialties being linked to a single peripheral hospital which involves the technique of one-to-many integration. The next stage is the many-to-one integration where multiple peripheral eClinics can be joined with single specialties. And finally multiple peripheral eClinics can be joined to multiple specialties. This would happen when the need for eClinics reaches its optimum and this involves the techniques of many-to-many integration.

According to the ViduSuwa concept, the eClinic location must be static (the patient must be assisted by a doctor at the peripheral hospital), while the eConsultation centre can either be a static location or even it can be dynamic in order to facilitate a mobile solution so that consultants can provide healthcare services to patients from anywhere in the globe. This implies that the 'eClinic location' is a variable which can be defined and is associated with the patients. 
All the above mentioned integration techniques are done with three main types of associations. They are patient-to-consultant, hospital-to-eClinics and patient-to-eClinics associations. The table below (table 3) presents how the integration techniques are implemented using the association types in the system.

Table 3: Integration Techniques

\begin{tabular}{llll}
\hline $\begin{array}{l}\text { External Process in the } \\
\text { eTeleConsultation }\end{array}$ & $\begin{array}{l}\text { Integration } \\
\text { Technique }\end{array}$ & $\begin{array}{l}\text { eClinic-to- } \\
\text { eConsultation } \\
\text { Roadmap }\end{array}$ & $\begin{array}{l}\text { Associations in the } \\
\text { mapping (Illustration) }\end{array}$
\end{tabular}

\begin{tabular}{lll}
\hline Point to Point eClinic & $\begin{array}{l}\text { One-to-One } \\
\text { Integration }\end{array}$ \\
Multiple Specialties & $\begin{array}{l}\text { One-to-Many } \\
\text { Integration }\end{array}$
\end{tabular}

$\begin{array}{llll}\text { Multiple eClinics } & \begin{array}{l}\text { Many-to-One } \\ \text { Integration }\end{array} \\ \begin{array}{lll}\text { Global Inter - Hospital } \\ \text { Network }\end{array} & \begin{array}{l}\text { Many-to-Many } \\ \text { Integration }\end{array} & \begin{array}{l}\text { Hospital-to- } \\ \text { eClinics, Patient-to- } \\ \text { eClinics }\end{array} \\ & \begin{array}{l}\text { Patient-to- } \\ \text { Consultant, } \\ \text { Hospital-to- } \\ \text { eClinics, Patient-to- } \\ \text { eClinics }\end{array}\end{array}$

One-to-one integration is the point-to-point eClinics where one peripheral hospital is connected only with single specialties. That is single specialties linked with single eClinic location. One-to-many is the next stage where a single eClinic location is linked with multiple specialties. Here the integration is done through patient-to-consultant associations. And also access rights have to be restricted to consultants in this stage. Consultants should not have access to all the patients in the EMR system. A consultant must have the access only to his/her patients. Other patients' profiles in the system should not be accessible from that particular consultant's login.

When moving to the next stage where single specialties can be linked with multiple eClinic locations with many-to-one integration, the hospital-to-eClinics and patient-to-eClinic associations are used. And the ultimate stage where multiple specialties can be linked with multiple eClinic locations is the many-to-many integration and this uses all three types of associations, hospital-to-eClinics, patient-to-eClinics, and patient-to-consultant associations. And access rights to patients must be restricted to the lower level at this stage. 


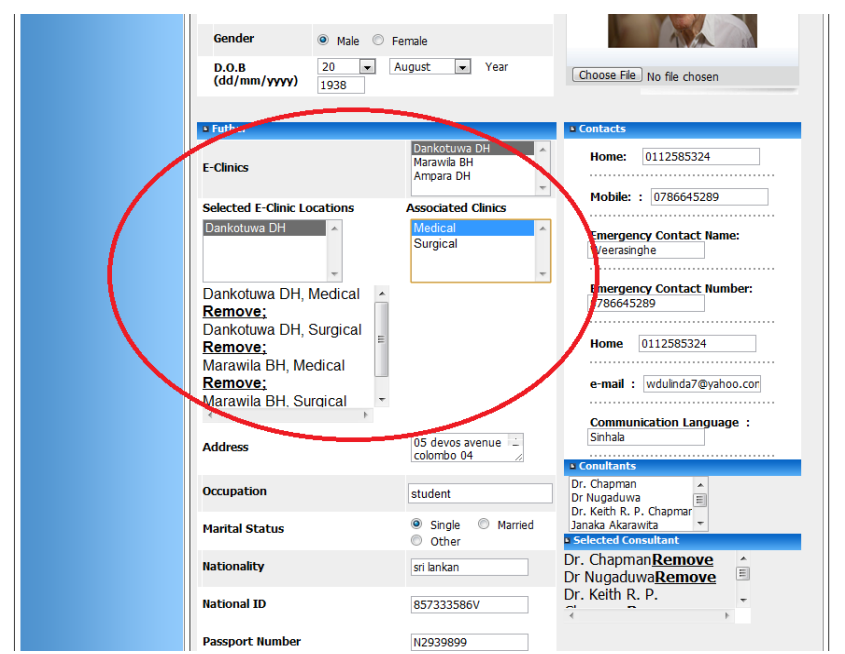

Figure 3(a): Patient to eClinics Assoication

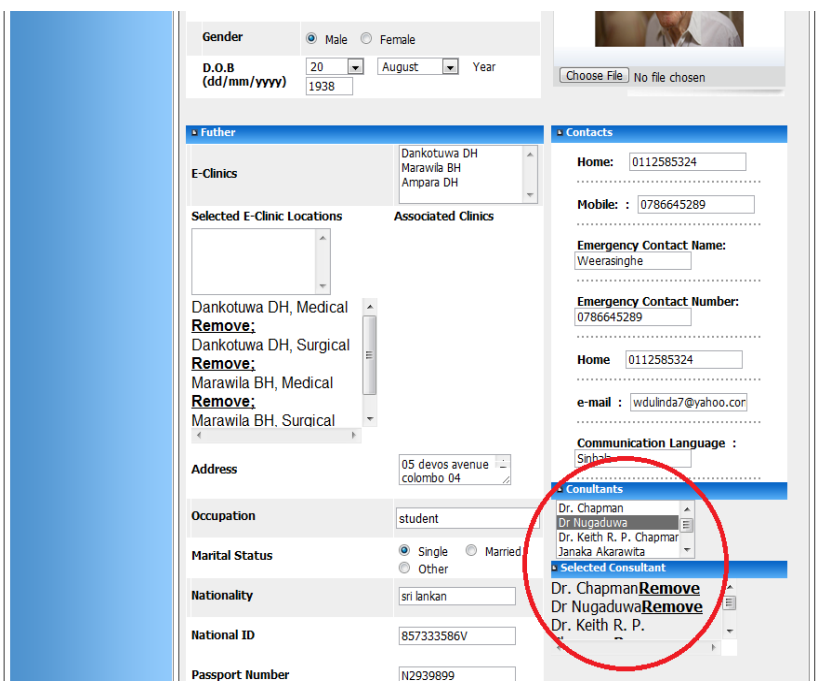

Figure (b):Patient to Consultant Association

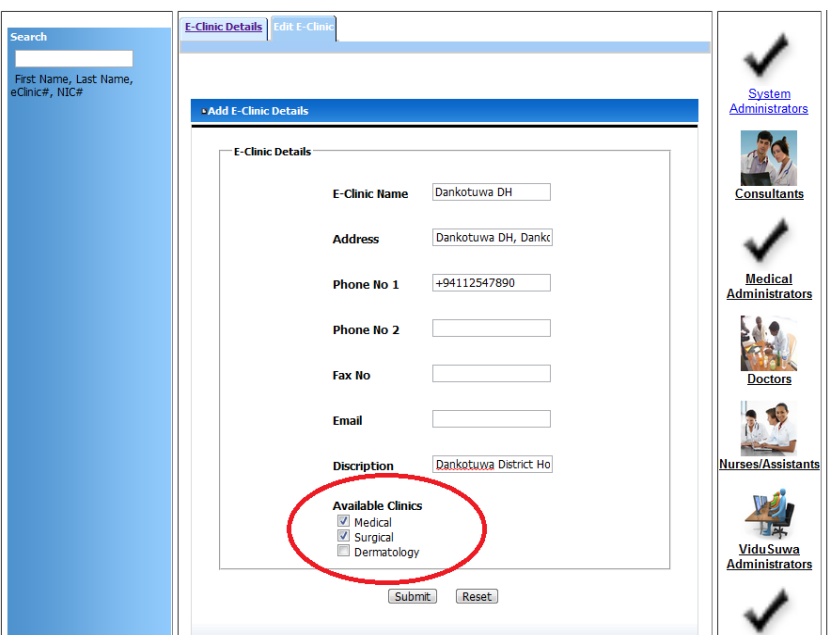

Figure 3(c): Hospital to eClinics Assoication 
To accomplish these integrations the three types of associations namely Patient-toConsultant, Hospital-to-eClinic and Patient-to-eClinic associations are implemented in the EMR system. Every patient in the system is associated with a list of consultants and a list of eClinic locations. A hospital is associated with a list of eClinics and a patient is associated with a list of eClinic locations which he/she is referred to. The figures 3(a), 3(b) and 3(c) illustrate how these three associations are done through the system interfaces.

\section{Security Enforcements}

When moving in to a wider network security becomes a major concern as the system deals with critical and sensitive information. Thus confidentiality of the information in the clinical information systems should be maintained in order to preserve patients' privacy and other health issues.

The Secure Socket Layer (SSL) protocol is incorporated which enforces secure transmission over the internet. Encryption techniques are used to store critical information in the database such as account details. And the back end is implemented using EJB technology which makes it harder to attack the back end and database.

Several policies and standards were adopted in order to comply with the manual process. Importantly, no deletion policy was incorporated which means a record cannot be deleted by any users. A user can only append medical records to the patients' clinical notes. It cannot be deleted by any authorised user. Records entered to the clinical notes by the consultant and the doctor would be updated with the date, time stamp and the user's name who has updated it. All the log-ins should be recorded in a system log to minimise the occurrence of unauthorised access. It is imperative to be in compliance with the Site Disclaimer, Privacy Policy and the Terms and Conditions of the system.

The adequate protection of patient health record requires limitations at all levels, i.e. collection, use, access, and disclosure. Access privileges are granted to the system users using role based access level security. The most critical feature in the 'User Management' module is the Role based User Access Privileges. Access privileges provide a level of security, preventing users from tampering with aspects of the in which system they don't belong and allows a system to provide customised interfaces to users based on their roles.

The system deals with five categories of users namely, Consultants, Doctors, Medical Administrators, Nurses and ViduSuwa Administrator. These user categories have different access privileges to the system according to their roles. For instance, Consultants and Doctors have the privilege of viewing adding and editing patient records while Nurses and Medical Administrators have only the read privilege.

These access rights must be limited even further when moving in to the next stages in the teleconsultation roadmap. The Consultants should not be given access rights to all the patients in the system. They must have the access only to their patients' profiles. This can be done through the patient-to-consultant association. Thus in order to give a Consultant access rights to a specific patient's records, that patient must be associated with the Consultant. In the patient's profile the Consultant must be selected from the list to associate with the patient.

A user with the Doctor role is only given access to patients registered to his/her 
hospital/eClinic location. The Doctor role is not involved in the one-to-many or many-tomany integration as the Consultant role. Thus doctors do not have to get access to patients registered to other eClinic locations. Users with the Nurse role can only register patients and add patient records. They do not have access to view patient records.

An account with the Medical Administrator role is given to every hospital registered to the system. The medical administrator has the rights to view all the patients' records in his/her hospital. In addition, the Medical Administrator has the rights to add user accounts to the system. So if a doctor wants to get registered to the system, it has to be done through the Medical Administrator.

The ViduSuwa Administrator role has the highest privileges in the system, as the user management module is accessible only by this particular role. The ViduSuwa Administrator can add, delete or edit user objects to the system and the associated access privileges can also be updated through the user management module. The figure 4 below depicts the roles and the access level hierarchy.

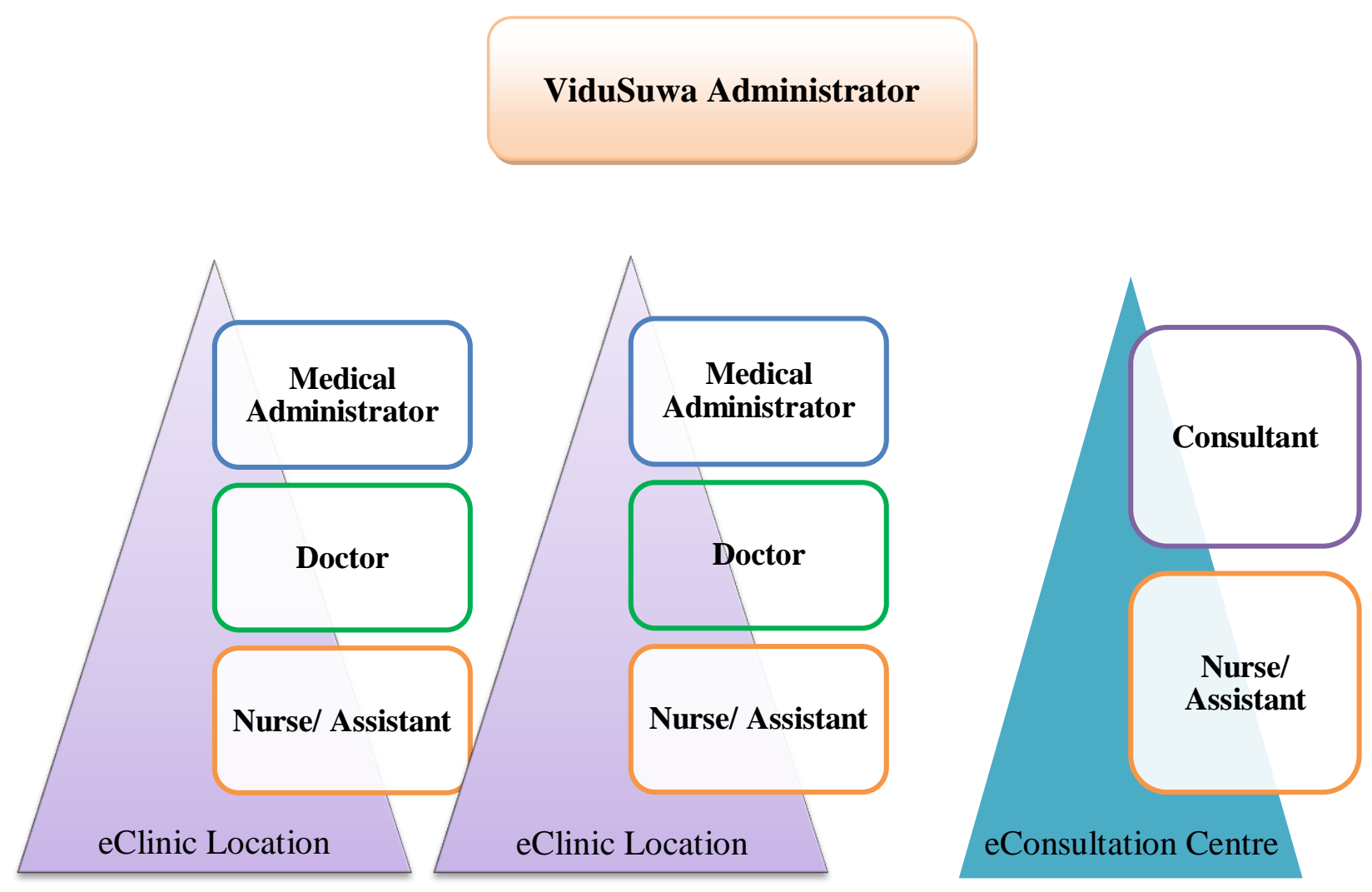

Figure 4: System Access Level Hierarchy

\section{Post Implementation Analysis}

After few eClinic trial sessions, all the ePatients were given a questionnaire to fill their appropriate comments. The analysis shows that there was a significant reduction in total 
travel cost $(90.94 \%)$, in travel distance $(80 \%)$ and travel time $(75 \%)$ after the solution was adapted to the hospital system.

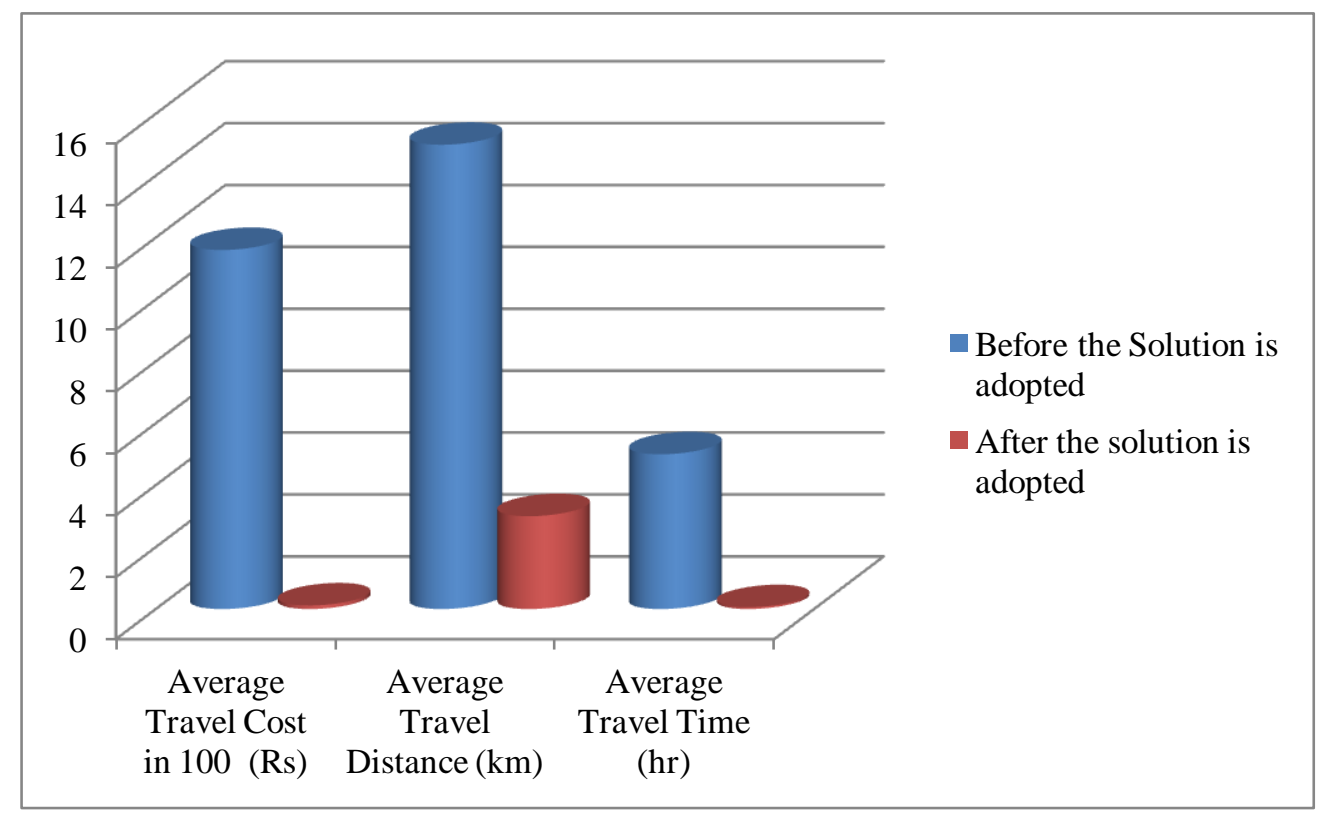

Figure 5: Post Implementation Analysis Results for Patients

Consultants and doctors are emotionally satisfied and accepted the easiness of using the system. After conducting a town hall meeting for the consultants of the National Hospital Colombo a questionnaire was given to capture their feedback. Twelve consultants participated in the survey analysis. The analysis was as follows (figure 6):

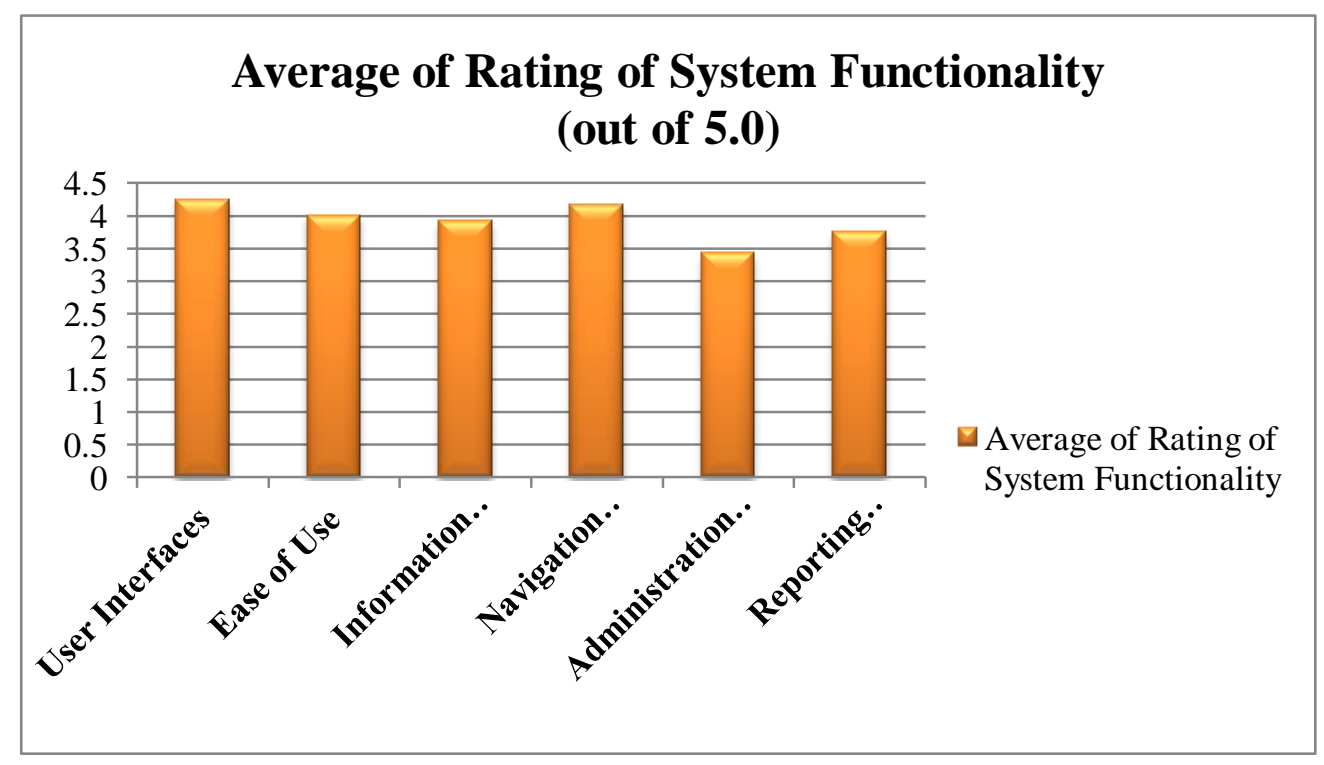

Figure 6: Average of the Ratings given by Consultants (out of 5.0)

Some interesting statistics are gathered after the solution is implemented in the hospitals. The analysis study is carried out throughout the period of July 2009 to July 2010. The following facts are obtained. 
- Number of System Users - 26

- Number of Consultants and Doctors registered to the system - 21

- Number of patients registered to the system - 106

The following charts (figure 7,8 ) show the ePatients distribution by age category and the number of ePatients for the eClinics.

\section{Number of Patients for eClinics}

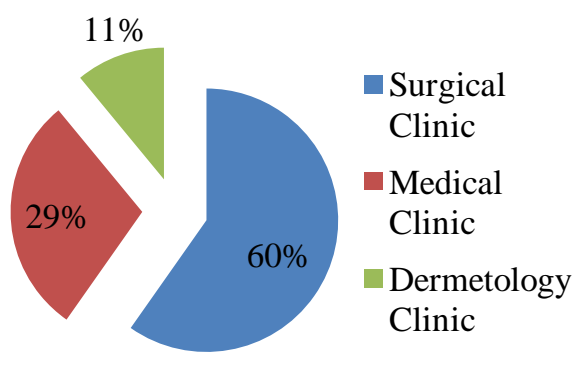

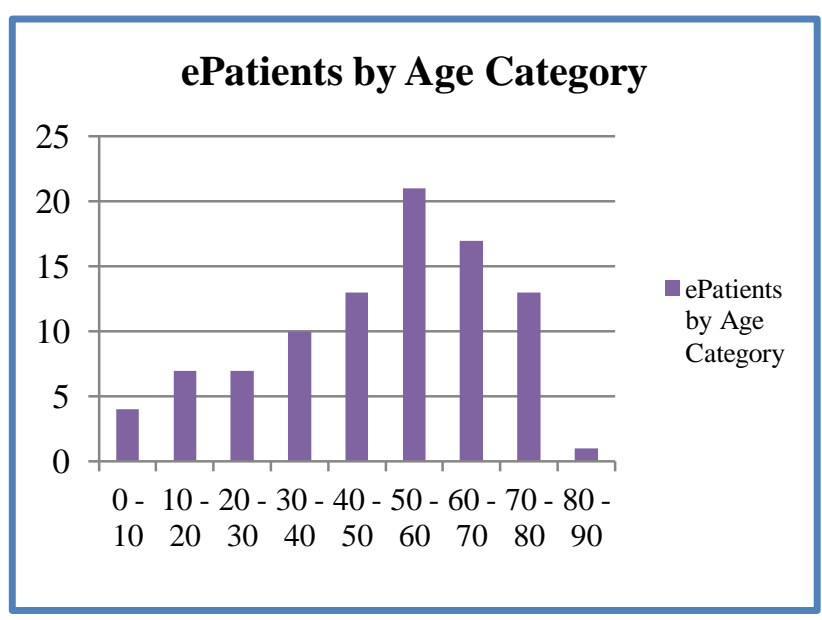

\section{Figure 7: Number of ePatients for the eClinics Figure 8: ePatients by Age Category}

Currently three eClinics participate in the eConsultations and they are surgical clinic, medical clinic and dermatology clinic. The eConsultation sessions for surgical clinics and dermatology clinics are conducted every week. The analysis shows that patients between the age of 40 years and 80 years are more likely to use the solution.

After the solution was adapted to the hospitals several visits were made to the hospitals in order to examine the attitudes of the medical staff and patients regarding the solution and the effectiveness of the solution in the context. We were able to see the positive attitudes among the staff and patients. The following are some of the interesting observation facts found out during the visits.

- Most of the medical staffs are interested in the concept and very enthusiastic about using the solution

- Every week at least one eConsultation session is being carried out

- The users are very familiar with technical environment

- Patients are attending the sessions with enthusiasm, comfortable, and satisfaction

- Medical staffs at the hospitals are trying to utilise the provided resources as much as possible

\section{Acknowldegement}

The pilot project was carried out at the Base Hospital Marawila and the District Hospital Dankotuwa which are the specialist eConsultation Centre and the Peripheral eClinic respectively. E-Consultations are conducted weekly in the fields of surgery and dermatology. The authors acknowledge the dedication and hard work of the Consultants, Doctors and staff of Marawila, Dankotuwa and the National Hospital Colombo, Director, all academic staff and students of University of Colombo School of Computing who have contributed to making 
ViduSuwa a success. Financial assistance for the ViduSuwa project was provided by the eSociety Programme of the Information and Communication Technology Agency of Sri Lanka (ICTA). The connectivity for the Pilot project is generously offered by Sri Lanka Telecom (SLT).

\section{Conclusion}

ViduSuwa EMR was designed and implemented under the GPL, with the prime motive of providing specialised healthcare services for people living in the developing world with less difficulty and expenditure. This system would hence enable the patients to receive Medical Consultation over the internet with the assistance of a doctor.

The system with its innate flexibility is capable of being adopted by both Health Institutes and Medical Specialists to provide, Consultation to patients. With the success of the pilot project, ViduSuwa has proven to reduce patient's cost, time and distance-to-travel in receiving medical consultations in the rural areas. In order to replicate the solution to other hospitals throughout the island, several integration techniques and security implementations are incorporated in to the EMR system. This is supposed to be done in a step-by-step approach using the teleconsultation roadmap. This paper discussed the integration techniques used in the EMR system to eTransform the external process in the roadmap. The EMR is constantly being upgraded to improve features as well as expand the system making it a dynamic and flexible entity according to the evolutionary approach.

In conclusion the integration techniques and security enforcements to the ViduSuwa EMR ensure sustainable, replicable and quality healthcare to all citizens in Sri Lanka and the experience can be shared and applied by the health sector of other developing nations to assure better healthcare for all citizens.

\section{References}

1. Ministry of Healthcare and Nutrition, Annual Health Bulletin of Sri Lanka for 2004-2005, Available from www.health.gov.lk/Annual HealthBulletin.htm. Accessed on Jul 1, 2008.

2. Chapman, K.R.P. \& Arunatileka S.M.K.D. Introducing a Patient Centric e-Health Solution for a Developing Country. IADIS eSociety 2009, Barcelona, Spain, 2009.

3. Saatviga S, Dinusha V,Wijethilake D, Wickramasinghe S.Y.Y.D, Arunatileka S.M.K.D, Chapman K.R.P, Senaviratne G.P. ViduSuwa: A Mobile Telemedicine Solution for Patients in Emerging Countries. eAsia 2009, Colombo, Sri Lanka, 2009.

4. Dinusha V, Arunatileka S.M.K.D, Chapman K.R.P, Senaviratne G.P, Saatviga S, Wijethilake D, Wickramasinghe S.Y.Y.D. Enhancing eHealth using M-Communication in Developing Countries. eIndia 2009, Hyderabad, India, 2009.

5. Filemed. Electronic Medical Records (EMR) and Appointment Scheduling Software. Available from http://www.filemed.com/. Accessed on Jul 18, 2010.

6. PatientOS. Open Source EMR. Available from http://www.patientos.org/. Accessed on Jul 27, 2010. 
7. Sourceforge. Hospital OS. Available from http://sourceforge.net/projects/hospitalos/files/. Accessed on Jul 27, 2010.

8. OpenEMR Home Page. Available from http://www.oemr.org/. Accessed on Jul 27, 2010.

9. OpenMRS Home Page. Available from http://openmrs.org/. Accessed on Jul 27, 2010.

10. Sourceforge. Medical. Available from http://medical.sourceforge.net/. Accessed on Jul 27, 2010.

11. Jack Wallen.(2009). Let your medical practice go open source with Gnumed. Available from http://www.ghacks.net/2009/10/20/let-your-medical-practicego-open-source-withgnumed/. Accessed on Jul 27, 2010.

12. Oscar. Brief Overview. Available from http://www.oscarcanada.org/aboutoscar/briefoverview. Accessed on Jul 28, 2009.

13. Chapman, K.R.P. \& Arunatileka S.M.K.D. The Teleconsultation Roadmap. Healthcom 2010, Lyon, France, 2010. 